\title{
Redo Robotic-Assisted Transcatheter Mitral Valve Replacement in a Patient with Mitral Annular Calcification
}

\author{
Andrew Frey ${ }^{1}$, James West ${ }^{1}$, Clifton Lewis ${ }^{2}$, Mustafa Ahmed ${ }^{2}$, Kyle Eudailey ${ }^{2}$, and Panos \\ Vardas $^{2}$ \\ ${ }^{1}$ Brookwood Baptist Health \\ ${ }^{2}$ University of Alabama at Birmingham
}

December 24, 2020

\begin{abstract}
Mitral valve replacement in the setting of mitral annular calcification (MAC) remains a surgical challenge fraught with several known complications. We present an innovative and hybrid approach involving robotic-assisted deployment of a SAPIEN S3 (Edwards Lifesciences, Irvine, CA) in the mitral position of a patient with severe MAC in the setting of previous sternotomy for aortic valve replacement. The robotic platform allowed avoidance of redo sternotomy, paravalvular leaks adjustment through excellent visualization from the right chest, and better assessment of the risk of left ventricular outflow tract obstruction. This report serves as an alternative technique for the management of mitral valve surgery associated with MAC in the era of transcatheter and minimally-invasive cardiac operations.
\end{abstract}

\section{Hosted file}

JCS - Redo rMVR in MAC.pdf available at https://authorea.com/users/385115/articles/500588redo-robotic-assisted-transcatheter-mitral-valve-replacement-in-a-patient-with-mitralannular-calcification

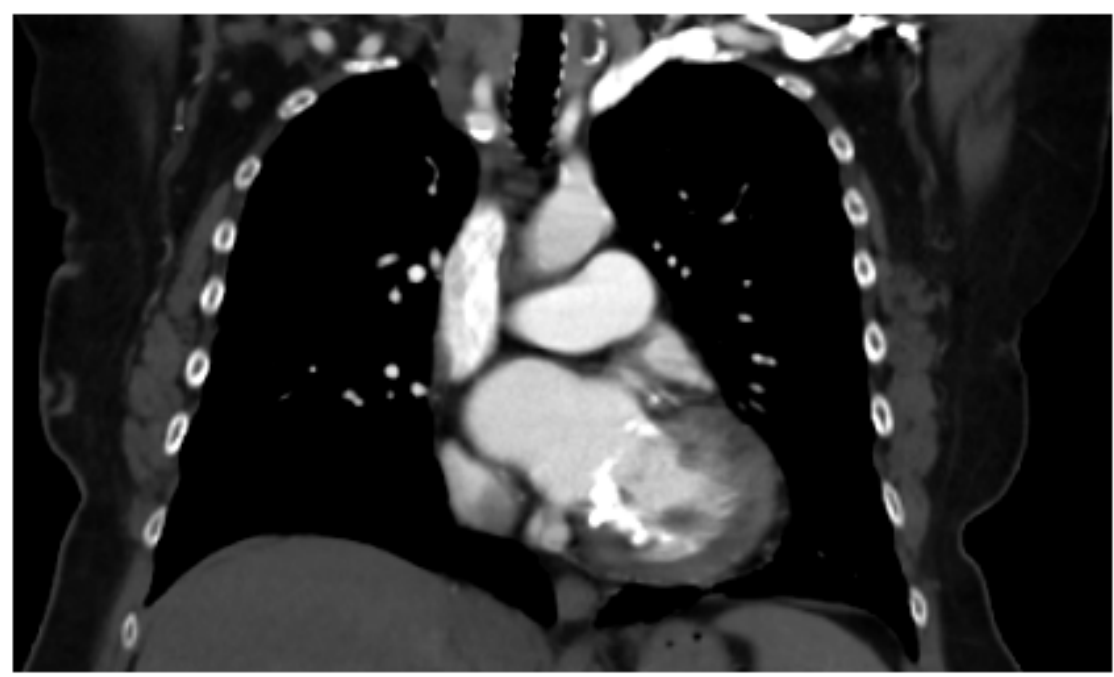

Figure 1: Visualization of MAC on preoperative $C T$ 


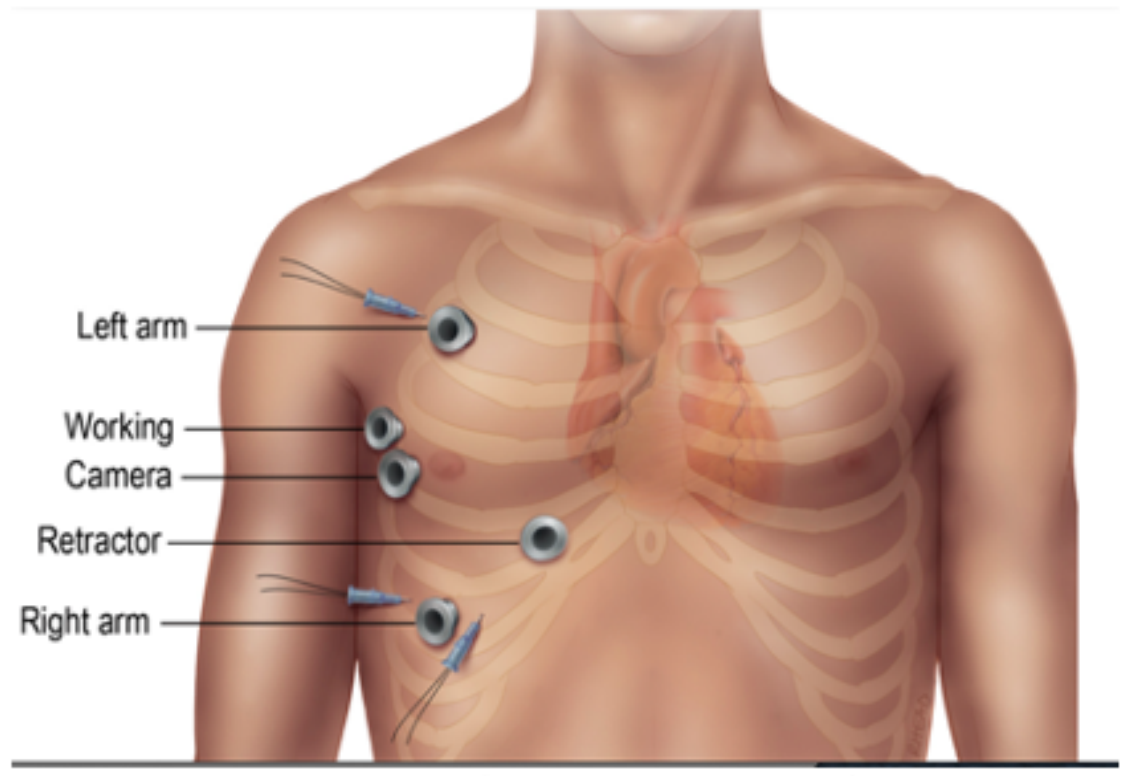

Figure 2: Schematic Illustration of Robotic Trocar Sites and functional use 